\title{
Correlation of Status of Mastoid with Outcomes of Myringoplasty with Cortical Mastoidectomy in Mucosal Otitis Media with High Risk Perforation
}

\author{
Asmita Shrestha', Hari Bhattarai ${ }^{2}$, Pabina Rayamajhi², Rabindra B Pradhananga ${ }^{2}$
}

\author{
Author(s) affiliation \\ 'Department of ENT-HNS, Pokhara \\ Academy of Health Science \\ 2Department of ENT-HNS, \\ Maharajgunj Medical Campus, \\ Ganesh Man Singh Memorial \\ Academy of ENT-Head \& Neck \\ Studies Tribhuvan University \\ Teaching Hospital, Institute of \\ Medicine, Kathmandu, Nepal

\section{Corresponding author} \\ Rabindra B Pradhananga, \\ MBBS, MS \\ rabindra9034@gmail.com
}

\section{Submitted}

Feb 7, 2021

\section{Accepted}

Mar 22, 2021

\begin{abstract}
\section{Introduction}

Chronic mucosal otitis media is one of the common disease prevalent in our society. This study was done to correlate the status of mastoid with outcomes of myringoplasty with cortical mastoidectomy in mucosal otitis media with high risk perforation.
\end{abstract}

\section{Methods}

This prospective, observational study was done at Department of Otorhinolaryngology and Head and Neck Surgery, Tribhuvan University Teaching Hospital. Thirty-four patients of agle 15 and above with chronic mucosal otitis media having high-risk perforation undergoing cortical mastoidectomy with myringoplasty were included. The status of middle ear, aditus, and mastoid air cells were assessed. Post-operatively, patients were assessed for graft uptake and hearing after three months. The post-operative graft uptake and hearing results were correlated with the peroperative status. Four patients who had preoperative sensorineural hearing loss were studied in terms of graft uptake only.

\section{Results}

The graft success rate in patients with normal mastoid air cells was $90 \%$ whereas in diseased cases was $71.4 \%$ which was statistically not significant with $p$ value 0.20 . The success rate in terms of hearing was $68.8 \%$ in normal mastoid whereas it was $64.3 \%$ in diseased mastoid which was statistically not significant with $p$-value of 1 .

\section{Conclusion}

In correlation with the status of mastoid air cells with graft uptake and hearing result, the observed differences were not statistically significant. However, averages of post-operative air conduction threshold and air-bone gap of all cases were better as compared to preoperative levels.

\section{Keywords}

Chronic mucosal otitis media, cortical mastoidectomy, high-risk perforation 


\section{INTRODUCTION}

$\mathrm{C}$ hronic otitis media (COM) implies a permanent abnormality of pars tensa or flaccida, most likely a result of earlier acute otitis media, negative middle ear pressure or otitis media with effusion. ${ }^{1}$ The perforation of tympanic membrane is usually treated by myringoplasty alone. Various factors determine the success of surgery such as age of patient, size and site of perforation, duration of dry middle ear prior to surgery, surgical approaches and techniques, contralateral ear status, experience of surgeon, primary or revision surgery, smoking status. ${ }^{2}$

Perforation of tympanic membrane with high chances of failure of surgery are considered as highrisk perforations which include patients requiring revision surgery, discharging ear, anterior perforation or perforation larger than $50 \% .^{3}$ Holmquist and Bergstrom had suggested that mastoidectomy improves the chance of successful tympanoplasty in non-cholesteatomatous chronic otitis media. ${ }^{4}$ However, this theory was opposed by Balyan et al. ${ }^{5}$ Additional mastoidectomy improves the ventilation of middle ear by buffering the pressure changes according to Boyle's law. ${ }^{6}$ It leads to prolongation of surgical time and cost and potential risk to structures like incus, dura, sinus, facial nerve. ${ }^{7,8}$

The tympanic membrane perforation removes sound protection from round window resulting in a tendency of sound to reach both round and oval windows at the same time canceling each other. This contributes to hearing loss upto $40-45 \mathrm{~dB} .{ }^{9}$ This study was conducted to evaluate the role of the peroperative status of mastoid, aditus and middle ear in terms of graft uptake and hearing outcome in chronic mucosal otitis media cases with high-risk perforation.

\section{METHODS}

A prospective, observational study was conducted in Department of ENT-Head and Neck Studies, Tribhuvan University Teaching Hospital, Kathmandu from August 2018 to November 2019. The study was conducted after approval from Institutional review committee and taking written consent from the patient or the guardian. Patients of all gender of age $\geq 15$ years with chronic otitis media mucosal with high risk perforation were included in the study.

High risk perforation was defined as:

- Perforation with quiescent or persistently discharging middle ear

- Subtotal - large central perforation involving all quadrants of pars tensa

- Total - large marginal perforation involving all quadrants of pars tensa

- Residual perforation with history of previous myringoplasty
The exclusion criteria included the patients undergoing myringoplasty for indications other than chronic otitis media like traumatic and in those with ossicular fixation and discontinuities, pure sensorineural hearing loss, patients were assessed for hearing only.

The patients underwent clinical examination and pure tone audiometry test within seven days prior to the operation. The air conduction and bone conduction threshold included the frequencies of 500,1000, 2000 and $3000 \mathrm{~Hz}$ according to American Academy of Otolaryngology-Head and Neck Surgery guidelines. ${ }^{10}$ The air-bone gap was calculated by taking the differences between air conduction and bone conduction threshold at the same time. The same procedure was done postoperatively after three months and the air-bone gap was calculated by taking the differences between post-operative air conduction with preoperative bone conduction. ${ }^{11}$

The status of the middle ear was classified into two categories either normal or diseased that included pus, granulations, edema, hyperemia. The status of the ossicular chain was noted. The status of mastoid air cells was also categorized into two groups either normal or diseased. The diseased included those having edematous mucosa and/or granulation tissue. Thorough removal of mastoid cells was done and the mastoid cavity was created. The aditus was then evaluated and categorized into two groups: patent or blocked. In case of blocked status, the cause of the blockage was noted whether due to edema or granulation tissue. The patency of aditus was then established which was confirmed by a free flow of normal saline from the mastoid to the middle ear or vice-versa.

The successful graft status was defined as a complete take up of graft. The perforation of any size was considered as a failure. A post-operative residual air-bone gap of $20 \mathrm{~dB}$ or less was considered as successful regarding the hearing outcome. ${ }^{12,13}$ Data was analysed using SPSS statistical software version 22. Descriptive (mean, standard deviation) and inferential statistics (Fisher exact test and paired t test) were used. The $p$ value $<0.05$ was considered to be statistically significant.

\section{RESULTS}

The total number of patients enrolled was 34 . All 34 were assessed for graft uptake whereas four cases with preoperative sensorineural hearing loss were excluded from hearing outcome evaluation. The age of the patients ranged from 16 years to 67 years with mean being $31.50 \pm 14.72$ years. Out of all, 17 cases were indicated for persistent ear discharge, seven of revision surgery and five each of total and subtotal perforation. 
Table 1. Correlation of per-operative findings with graft uptake $(n=34)$

\begin{tabular}{lccc}
\hline $\begin{array}{c}\text { Peroperative } \\
\text { status }\end{array}$ & $\begin{array}{c}\text { Number } \\
\text { of cases } \\
(\mathrm{n}=34)\end{array}$ & $\begin{array}{c}\text { Number of } \\
\text { successful } \\
\text { graft uptake } \\
(\mathbf{n = 2 8 )}\end{array}$ & p-value \\
\hline $\begin{array}{l}\text { Middle ear status } \\
\text { Normal }\end{array}$ & 16 & $13(81.3)$ & 1.00 \\
$\begin{array}{l}\text { Diseased } \\
\text { Status of aditus }\end{array}$ & 18 & $15(83.3)$ & \\
$\begin{array}{l}\text { Patent } \\
\text { Blocked }\end{array}$ & 20 & $19(95)$ & 0.06 \\
$\begin{array}{l}\text { Mastoid air cells } \\
\text { system }\end{array}$ & 14 & $9(64.3)$ & \\
$\quad$ Normal & 20 & $18(90)$ & 0.20 \\
Diseased & 14 & $10(71.4)$ & \\
\hline
\end{tabular}

Peroperatively, there were 16 cases with normal middle ear while in 18 middle ear was diseased. There were 20 patients with patent aditus and 14 with blocked. Out of those with blocked aditus, seven were because of granulation tissue while rest had edematous mucosa. Similarly, in 20 patients mastoid air cells was normal while in 14 it was diseased. Granulation tissue was present in 10 out of 14 patients while rest had edematous mucosa.

In this study, 28 patients had successful graft uptake with six cases of failure resulting in a successful uptake of $82.4 \%$. Out of 16 cases with normal middle ear status, 13 patients had successful graft uptake with a success rate of $81.3 \%$ whereas in those with diseased middle ear, 15/18 patients had successful graft uptake with a success rate of $83.3 \%$ which was not statistically significant. Similarly, the graft uptake rate in patent aditus group was 95\% (19/20) and blocked group was $64.3 \%$ (9/14) which was statistically not significant. Among the group with normal mastoid air cells, the success rate was $90 \%(18 / 20)$ and $71.4 \%(10 / 14)$ in diseased mastoid air cells group which was also statistically not significant. The details are shown in Table 1.

The average air conduction of all 30 cases preoperatively was $44.20 \pm 13.90 \mathrm{~dB}$ and postoperatively was $33.2 \pm 17.62 \mathrm{~dB}$ with a gain of 11 $\mathrm{dB}$ with $\mathrm{p}$-value of $<0.001$ that was statistically significant. Similarly, the average pre and postoperative air-bone gaps were $26.50 \pm 10.34 \mathrm{~dB}$ and $15.50 \pm 12.52 \mathrm{~dB}$ respectively with a gain of $11 \mathrm{~dB}$ and p-value of $<0.001$ which was statistically significant as shown in Table 2.

There were 20 patients (66.7\%) who had postoperative $A B G$ within $20 \mathrm{~dB}$ and 10 patients $(33.3 \%)$ with more than $20 \mathrm{~dB}$. Seven patients with
Table 2. Average pre and post-operative ACT and ABG of all patients $(n=30)$

\begin{tabular}{lccccc}
\hline Variables & $\begin{array}{c}\text { Pre } \\
\text { operative } \\
(\mathrm{dB})\end{array}$ & $\begin{array}{c}\text { Post } \\
\text { operative } \\
(\mathrm{dB})\end{array}$ & $\begin{array}{c}\text { Gain } \\
(\mathrm{dB})\end{array}$ & $\begin{array}{c}\mathrm{p}- \\
\text { value }\end{array}$ \\
\hline $\mathrm{ACT}$ & $44.20 \pm 13.90$ & $33.20 \pm 17.62$ & 11 & $<0.001$ \\
$\mathrm{ABG}$ & $26.50 \pm 10.34$ & $15.50 \pm 12.52$ & 11 & \\
\hline ACT : Air conduction threshold; $A B G$ : Air bone gap
\end{tabular}

normal middle ear mucosa and13with diseased middle ear had post-operative ABG within $20 \mathrm{~dB}$. These differences were statistically not significant. Similarly, the success rate of patient with patent aditus was 75\% (12/16) and with blocked aditus was $50 \%$ (7/14) which was statistically not significant. The success rate for normal mastoid air cells was $68.8 \%(11 / 16)$ and for diseased was $64.3 \%$ (9/14) which was statistically not significant. The details are presented in Table 3.

The average $A B G$ gain of all 12 cases with normal middle ear was $8.34 \mathrm{~dB}$ whereas it was $12.78 \mathrm{~dB}$ in 18 cases with diseased middle ear mucosa. The statistically observed differences of both group are presented in Table 4.

The average $A B G$ gain of 16 cases with patent aditus was $11.94 \mathrm{~dB}$ whereas in 14 cases with blocked aditus, it was $11.93 \mathrm{~dB}$. These observed differences were also statistically significant as presented in Table 4.

Similarly, there was a gain of $11.07 \mathrm{~dB}$ in 16 cases with normal mastoid air cells whereas in those with diseased mastoid air cells, it was $10.57 \mathrm{~dB}$. These observed differences were also statistically significant. as presented in Table 4.

Table 3. Correlation of per-operative findings with average post-operative $A B G(n=30)$

\begin{tabular}{lccc}
\hline \multicolumn{1}{c}{ Factors } & $\begin{array}{c}\text { Number } \\
\text { of cases } \\
(\mathbf{n}=30)\end{array}$ & $\begin{array}{c}\text { Post- } \\
\text { operative } \\
\text { ABG } \\
\text { upto } 20 \mathrm{~dB}\end{array}$ & p-value \\
\hline $\begin{array}{l}\text { Middle ear status } \\
\text { Normal }\end{array}$ & 12 & $7(58.3)$ & 1.00 \\
$\begin{array}{l}\text { Diseased } \\
\text { Status of aditus }\end{array}$ & 18 & $13(72)$ & \\
$\begin{array}{l}\text { Patent } \\
\text { Blocked }\end{array}$ & 16 & $12(75)$ & 0.06 \\
Mastoid air cells & 14 & $7(50)$ & \\
system & & & \\
Normal & 16 & $11(68.8)$ & 0.20 \\
Diseased & 14 & $9(64.3)$ & \\
\hline
\end{tabular}


Table 4. Correlation of peroperative fingdings with average pre and post-operative hearing in terms of $A B G(n=30)$

\begin{tabular}{|c|c|c|c|c|c|}
\hline Peroperative status & $\begin{array}{c}\text { Number } \\
\text { of cases } \\
(n=30)\end{array}$ & $\begin{array}{l}\text { Pre-operative } \\
\text { ABG (dB) }\end{array}$ & $\begin{array}{l}\text { Post-perative } \\
\text { ABG (dB) }\end{array}$ & $\begin{array}{l}\text { Gain } \\
(\mathrm{dB})\end{array}$ & $p$-value \\
\hline \multicolumn{6}{|l|}{ Middle ear status } \\
\hline Normal & 12 & $27 \pm 11.90$ & $18.66 \pm 15.42$ & 8.34 & 0.10 \\
\hline Diseased & 18 & $26.17 \pm 9.51$ & $13.39 \pm 10.08$ & 12.78 & $<0.001$ \\
\hline \multicolumn{6}{|l|}{ Status of aditus } \\
\hline Patent & 16 & $25.25 \pm 12.09$ & $13.31 \pm 11.44$ & 11.94 & 0.01 \\
\hline Blocked & 14 & $27.93 \pm 8.10$ & $16.00 \pm 12.99$ & 11.93 & 0.001 \\
\hline \multicolumn{6}{|l|}{ Mastoid air cells system } \\
\hline Normal & 16 & $26.13 \pm 11.44$ & $15.06 \pm 11.13$ & 11.07 & 0.02 \\
\hline Diseased & 14 & $26.57 \pm 9.78$ & $16.00 \pm 14.36$ & 10.57 & 0.002 \\
\hline
\end{tabular}

\section{DISCUSSION}

Chronic mucosal otitis media is one of the commonest diseases prevalent in our community usually treated by myringoplasty. Addition of concomitant cortical mastoidectomy with myringoplasty is one of the techniques accepted by several surgeons to deal with problem of increased graft failure rate in high risk situations. 6,14,15 The main aim of surgery is to eradicate the sequestered mastoid air cells and create a mastoid cavity with patent aditus to keep middle ear ventilated.

Frade et al. ${ }^{16}$ demonstrated that subtotal perforations were associated with reduced success rate. These perforations are at high risk of re-perforation, retraction pockets, revision surgeries and are more difficult to treat due to less extensive tympanic membrane margins to support graft survival and less tension to resist tympanic retraction postoperatively. ${ }^{17}$ Dangol et al. ${ }^{2}$ found the graft uptake $83.7 \%$ in dry ear, $81.2 \%$ in quiescent ear and $75 \%$ in actively discharging ear although the result was statistically not significant. The persistent discharge may lead to the displacement of graft, infection of graft material resulting in failure. However, some authors believe that there is no role of middle ear environment in the prognosis of surgery. ${ }^{18}$ Faramarzi et al. ${ }^{19}$ in their comparative study of the outcomes between primary tympanoplasty and revision tympanoplasty found the graft success rate higher in the primary group (96.6\%) as compared to the revision group (78.2\%) which was statistically significant although there was no significant difference in hearing outcome. The possible reason for this significant difference in graft uptake result could be due to compromised vascularity of middle ear in revision surgery. ${ }^{19}$

The per-operative status of aditus is an important factor in determining the success of surgery as it is responsible for the aeration of mastoid air cells through the middle ear. There are two pathways responsible for aeration of the middle ear: via eustachian tube anteriorly and via tympanic isthmus. ${ }^{20}$ The tympanic isthmus between the medial part of posterior incudal ligament and tensor tendon provides aeration to epitympanic compartments. The mesotympanic and hypotympanic spaces receive aeration directly from eustachian tube. Thus, the obstruction of aditus contributes to the pathological conditions in otitis media. Besides, it may contribute to failure following tympanoplasty by interfering with the aeration of epitympanum. Bahgat et al. ${ }^{20}$ in their study of 50 adult cases undergoing cortical mastoidectomy with myringoplasty evaluated the status of aditus endoscopically. They found $10(20 \%)$ cases had totally blocked aditus by unhealthy, thickened, and edematous mucosa. Of the central perforations, the incidence of blocked aditus increased more in cases with subtotal central perforations. However, they did not correlate the status of aditus with postoperative outcomes.

Any size of residual perforation in the tympanic membrane was considered as a failure of graft uptake in this study. The overall successful graft uptake rate in this study was $82.4 \%$. When breaking down the graft uptake rate with inclusion criteria, the successful uptake was seen in six $(85.7 \%)$ out of seven cases of revision surgery, 14/17 (82.4\%) patients with persistent discharge, three $(60 \%)$ out of five with total perforation and all five patients $(100 \%)$ with subtotal perforation. The success rate is comparable to that of Albu et al. ${ }^{21}$ which was $82.8 \%$. Kaur et al. ${ }^{22}$ had a success rate of $88 \%$. Kaur had excluded the cases with total perforation which could have led to a higher success rate as compared to this study. In this study, the relatively high failure rates could be related to inclusion of only high risk perforations and uniform surgical techniques performed on all the ears, as dictated by the strict study protocol, rather than to the demands of the individual operations. 
While correlating status of the middle ear with graft uptake, better uptake result of $83.3 \%$ was seen with diseased middle ear however observed difference was not statistically significant. Unlike our result Garg et al. in their study of 12 out of 40 cases with mucoid discharge had $92 \%$ successful graft uptake. This could be related to a small sample size of this study. Black and Wormald ${ }^{23}$ noted that the condition of ear during surgery didn't make a difference in graft take rate. Caylan ${ }^{24}$ however found that the graft take-up was higher in discharging cases and explained the reason to be the increase in vascularity.

While correlating status of aditus with graft uptake, better uptake result of $95 \%$ was seen with the patent aditus. This observed difference also was not statistically significant. Similarly, graft uptake results were better with a normal mastoid air cells as compared to diseased status even though the difference was not statistically significant. We could not find similar studies in literature that could match our methodology for comparison of our findings. However, these findings grossly point towards the necessity of clearing disease from mastoid and obtaining a patent aditus during surgery for better graft results in high risk situations.

The degree of air-bone gap depends on various factors which include the size of perforation, erosion of the ossicular chain, granulation tissue and tympanosclerosis around the ossicular chain which can reduce its mobility. ${ }^{1}$ The status of ossicles play an important role in determining the hearing improvement post-operatively regardless of the status of mastoid. Eliades et al. ${ }^{12}$ noted that in studies where the hearing was separately analyzed for patients with an intact ossicular chain, there was a net improvement. In this study, 7/30 cases had worsening in post-operative $A C T$ and $A B G$ which consisted of six patients with failure of graft uptake. One case although had graft uptake, the postoperative hearing got deteriorated. The reasons for the deterioration of post-operative hearing level even in cases with graft uptake could be development of adhesions, granulation tissue or lack of effectively vibrating graft. Literature in various studies also report a decrease in post-operative hearing in some cases.

On correlating the peroperative status of middle ear with hearing outcome in terms of $A B G$, there was improvement in both groups. Although it was not statistically significant in normal group, the diseased middle ear group had statistically significant improvement. Similarly, patients with both the patent and blocked aditus had statistically significant hearing improvement. The patients with blocked aditus had highly statistically significant hearing improvement implying the importance of establishing patency in diseased group. The patients with both the normal and diseased mastoid air cells also had statistically significant hearing results.

Complications were also recorded in this study. Only in one patient $(2.9 \%)$, sinus plate was iatrogenically exposed. However, there was no untoward incident peroperatively. There was one case of postoperative wound infection which was just $2.9 \%$ of total cases. Singha et al..$^{25}$ noted wound infection in $9.5 \%$ cases. According to Mishiro et al. ${ }^{13}$ performing mastoidectomy adds time, cost, and increased risk of post-operative complications which could be the reason for most of the surgeons being reluctant to perform mastoidectomy. In this study, surgery was done by either an experienced surgeon or under their strict supervision. This supports the evidence that concurrent mastoidectomy is not associated with increased complication rate especially if done by an experienced surgeon.

The present study addresses only short-term graft uptake and hearing results which may change with time. The actual outcome of the surgery would have been known had there been more number of patients been followed up for longer duration postoperatively.

\section{CONCLUSION}

In correlation with the status of mastoid and middle ear with graft uptake, the observed differences were not statistically significant. The averages of postoperative ACT and ABG were better as compared to the preoperative levels and these differences were statistically significant. However, correlating the peroperative status of mastoid and middle ear with post-operative hearing outcome, the observed differences between normal and diseased were not statistically significant.

\section{CONFLICT OF INTEREST}

None declared.

\section{REFERENCES}

1. Browning GG, Weir J, Kelly G et al. Chronic otitis media, In: Watkinson JC, Clarke RW (Eds).Scott-Brown's Otorhinolaryngology and Head and Neck Surgery. Eighth edition. New York: Taylor and Francis Group; 2018. pp. 977-1020.

2. Dangol K, Shrivastav R. Study of Various Prognostic Factors Affecting Successful Myringoplasty in a Tertiary Care Centre. Int Arch Otorhinolaryngol. 2017 Jul;21(3):250-4.

3. Dornhoffer J. Cartilage tympanoplasty: Indications, techniques, and outcomes in a 1,000-patient series. Laryngoscope. 2003 Nov;113(11):1844-56.

4. Holmquist J, Bergstrom B. The Mastoid Air Cell System in Ear Surgery. Arch Otolaryngol 1978 Mar;104(3):127-9.

5. Balyan F, Celikkanat S, Aslan A et al. Mastoidectomy in noncholesteatomatous chronic suppurative otitis media: Is it necessary? Otolaryngol Head Neck Surg. 1997 Dec;117(6):592-5.

6. Ruhl CM, Pensak ML. Role of Aerating Mastoidectomy in Noncholesteatomatous Chronic Otitis Media. Laryngoscope. 1999 
Dec ;109(12):1924-7.

7. Bhat KV, Naseeruddin K, Nagalotimath US et al. Cortical mastoidectomy in quiescent, tubotympanic, chronic otitis media: is it routinely necessary? J Laryngol Otol. 2009 Apr;123(4):383-90.

8. Adunka OF, Buchman CA. Mastoidectomy. In: Otology, Neurootology and lateral skull base surgery. First edition. New York: Thieme Medical Publishers; 2011.pp 295-96.

9. Athanasiadis A. Tympanoplasty: tympanic membrane repair. In: Gulya AJ, Minor LB, Poe DS (Eds). Glasscock-Shambough Surgery of the ear. Sixth edition. USA. People's Medical Publishing House; 2010. pp. 465-88.

10. Monsell EM. New and revised reporting guidelines from the Committee on Hearing and Equilibrium.Otolaryngol Head Neck Surg. 1995 Sep;113(3):186-7.

11. Harder $H$, Jerlvall L, Kylen $P$ et al. Calculation of hearing results after tympanoplasty. Clin Otolaryngol Allied Sci. 1982 Aug;7(4):221-9.

12. Eliades SJ, Limb CJ. The role of mastoidectomy in outcomes following tympanic membrane repair: A review: Role of Mastoidectomy During Tympanoplasty. Laryngoscope. 2013 Jul;123(7):1787-802.

13. Mishiro Y, Sakagami M, Takahashi Y et al. Tympanoplasty with and without mastoidectomy in non cholesteatomatous chronic otitis media. Eur Arch Otorhinolaryngol. 2001 Jan;258(1):13-5.

14. McGrew BM, Jackson G, Glascock ME III. Impact of mastoidectomy on simple tympanic membrane perforation repair. Laryngoscope. 2004 Mar;114(3):506-11.

15. Tos M. Manual of Middle Ear Surgery. New York: Thieme Medical Publishers, 1993.

16. Frade CG, Castro CV, Cabanas ER et al. Prognostic factors influencing anatomic and functional outcome in myringoplasty.
Acta Otorrinolaringol Esp. 2002 Dec;53(10):729-35.

17. Kulduk E, Dundar R, Soy FK et al. Treatment of large tympanic membrane perforations: medial to malleus versus lateral to malleus. Indian J Otolaryngol Head Neck Surg. 2015 Jun;67(2):173-9.

18. Onal K, Uguz MZ, Kazikdas KC et al. A multivariate analysis of otological, surgical and patient-related factors in determining success in myringoplasty. Clin Otolaryngol. 2005 Apr; 30(2):115120.

19. Faramarzi M, Shishegar M, Tofighi SR et al. Comparison of Grafting Success Rate and Hearing Outcomes between Primary and Revision Tympanoplasties. Iran J Otorhinolaryngol. 2019 Jan; 31(102):1117.

20. Bahgat M. Patency of the Aditus Ad Antrum in Tubotympanic Chronic Suppurative Otitis Media. Otolaryngol Head Neck Surg. 2015 Feb ;152(2):331-5.

21. AlbuS, Trabalzini F, Amadori M. Usefulness of cortical mastoidectomy in myringoplasty. Otol Neurotol. 2012 Jun; 33(4):604-9.

22. Kaur M, Singh B, Verma BS et al. Comparative evaluation between tympanoplasty alone and tympanoplasty combined with cortical mastoidectomy in non cholesteatomatous chronic suppurative otitis media in patients with sclerotic bone. ISOR-JDMS. 2014;13(6):405.

23. Black J, Wormald P. Myringoplasty: Effects on hearing and contributing factors. S Afr Med J. 1995 Jan; 85(1): 41-3.

24. Caylan R, Titiz A, Falcioni M, et al. Myringoplasty in children: factors influencing surgical outcome. Otolaryngol Head Neck Surg.1998 May;118(5):709-713.

25. Singha V, Debbarma A. Type 1 tympanoplasty with cortical mastoidectomy: results and complications. JEMDS.2015 Oct; 4(82):14348-53. 